\title{
The Changing Nature of Work-Life Balance in Nigerian Higher Institutions
}

\author{
Abdulraheem, Issa Ph.D \\ Department of Business and Entrepreneurship, College of Humanities, Management and Social Sciences Kwara \\ State University, Malete, Ilorin, Nigeria.
}

\begin{abstract}
The Nigerian higher education is continuously changing in terms of focus and expansion. The changes are therefore putting pressure on the work and expectations of both academic and academic support staff and affecting work life balance. The objective of this paper is to examine some taken for granted assumption of Work Life Balance (WLB) in Nigerian higher education as it affects workers' performance and productivity. Using qualitative method and relying on interview and observation, twenty eight academic staff and twenty two academic supports were interviewed from Kwara State University, Malete, Nigeria. It was found that work life balance is one of the major factors affecting workers' performance and productivity. It was also discovered that the long hours of work including weekends and public holidays of academic staff is due to additional responsibilities and shortage of staff. The paper recommends that government and various institutions should take proactive approach to work life balance. The paper recommends that academic staff should be given limited administrative responsibilities and a reduction in teaching workloads.
\end{abstract}

Keywords: Culture, Higher education, Shift work, Work Life Balance, Work load.

\section{Introduction}

The dichotomy between the state and federal institutions, the stage of the institution, the continuous change in the objectives of the institution and the profit oriented system have great impact on workers' work life balance. There are taken for granted assumptions which need to be examined and which direct and structure the research on Work Life Balance (WLB) (Lewis, et al, 2007). The objective of this paper is to examine some of the taken for granted in work-life balance in Nigerian higher education with a view to examining the effect on workers' performance and productivity. It is always assumed that staff of the universities should perform their duties in respective of the work load and effect on other social life if they don't want to risk losing their jobs. Even if they perform the work, they could perform better if the management is sensitive to workers' work life balance.

The concept of work- life balance in relation to workers' performance and productivity in Nigerian higher education has not been properly addressed. Work life balance affect workers' performance and productivity. Productivity is the ratio between input and output. Productivity is a mixture of the factors of land, material, machine and labour. There are four class factors: land, material, machine and labour. The focus of this paper is on the fourth element, labour. Improved productivity from labour might be improvement in the work methods. It is possible to have same input with an increase in output, by increasing output faster than input, or by decreasing input more the output decrease. Obtaining better productivity is a shared responsibility of the workers, the society and the providers of capital.

\section{Nigerian higher education system}

Change in higher education is not limited to Nigeria but higher educational institutions all over the world have also experiencing some forms of rapid changes over the past two decades. They have been subjected to globalisation and increase in competition which have led to commoditisation of knowledge and changes in the labour process (Parker and Jary, 1995; Fletcher, 2007: 269). In order to achieve economic development and provide quality education to its citizens, the Nigerian government established some higher institutions of learning. Higher education could be defined in different ways depending on the context but Akpan (1987) equate it with university education. It could also be regarded as tertiary level education. However, a comprehensive definition of higher education was provided in the Nigerian National Policy on Education (1981, p.72), which 'covers the post-secondary section of the national educational system which is given in Universities, Polytechnics, and Colleges of Technology, Colleges of Education and Advanced Teachers Colleges, correspondence colleges and such institutions as may be allied to them'.

\section{Work-life balance in Nigerian higher education context}

In order to view and understand the achievement of educational objectives of the Nigerian higher education effectively and efficiently it is necessary to examine various concepts that might affect the system. 
Such concepts that relate to performance of staff in the work place include work life balance. Effective performance of workers will enhance the achievement of educational objective of the university and it therefore important that factors that might affect this performance should be address.

The rationale behind the concept of work-life balance is that everyone should have a good and complete life in which a sufficient amount of time is given to both work and non-work lives (Kesting and Harris, 2009; Kossek, Lewis, and Hammer, 2012). Work Life Balance is associated with different notions such as conflict, integration and balance, crossover and such programmes on the provision of flexible work, diversity management and wellbeing outcome. However, the discussion and debate on WLB is reconstructed within organisational workplace (McDonald, et al, 2012)

Survival is the priority of most workers and little attention is given to family issue. The first consideration of an average Nigerian searching for job is financial benefit before considering the family. In some cases, it is believed that if you have a good job (with higher pay), family members and other social activities are not important and can be compromised. Some wives will prefer their husbands to spend longer hours at work place and bring home enough money to cater for the family. Therefore, these types of husbands will prefer to work in a department where there will be opportunity for overtime with pay.

However, it is not all the overtimes that are compensated monetarily. This depends on the department and the job role. For example, the management staff have no scheduled hours of work and do not receive overtime pay. Similarly, staff working in the department that could be busy at a point, maybe at the end of the month while preparing staff salary or a staff working with superior that is required to work long hours do not receive overtime pay. These staff benefit from the magnanimity of their boss at the end of the extra hours done in terms of giving them money from their pocket or rating them high during the promotion exercise.

\section{Work-Life Balance Literature}

The concept of work life is a key issue in current academic debate, practitioners and government (Eikhof, Warhurst, Hawnschlel, 2007). Work - life balance is one of the most relevant Human Resource practices in relation to productivity and performance of the organisation (Legarra - Leiva, Sanchez - Vidal and Legarra - Nararro 2012).

There is growing aspiration of people (Sturges and Guest, 2004) to balance their work with other aspect of life. This is as a result of the growing responsibilities of both academic and academic support staff in an academic environment devoting long hours to work. Felstead, et al, (2002) defined WLB as "individuals' ability, irrespective of age and gender, to find a life rhythm that allows them to combine their work with other responsibilities, activities and inspirations".

The aim of work life balance is to improve workers' conditions through altering work practices (Atkinson and Hall, 2009). The main thrust and perception of work life balance include the negative attitude towards work, the problem of work long hours, separation of work from life and the target is on women with the responsibility of child care. It is assumed that workers have lot of work, long hours and out of office work, characterised of typical Nigerian higher institutions. Similarly, employers are also interested in work - life balance and flexible working hours because of the impacts these might have our productivity.

There are different perspectives to the concept of WLB because of the implications of the social, economic and political factors impacting on the women's role, work systems, organisational structure, family and the society (Fleetwood, 2007). WLB is now pervasive and there is the need therefore to examine the challenges facing its implementations because the practice of WLB according to Fleetwood (2007) has become disconnected from the employee's experiences. According to McDonald, et al (2012), different organisations have different focus and practices arising from different conditions under which their organisations operate and which might lead to disconnection from WLB goals.

The changing nature of work, according to Waller and Ragsdell (2012) has been affecting work life balance negatively especially making staff accountable to their work and promotion. The increase in long hours of work may include organisational downsizing, job insecurity of those working harder for fear of losing their jobs and economic recession (Burke and McAteer, 2007). Employers demands and institutional nature of work and employment has tended to constrain work hours in established patterns.

Work life balance can increase the incidence of stress which can lead to high turnover rate and absenteeism which have impact on organisational productivity and staff performance. The common source of stress is the work life conflicts which are caused by the multiple roles of individual with limited time (Carlson et.al 2009). This conflict affects the general wellbeing of the employee.

Work load and job design have impact on work life balance of employees in Nigerian higher education. Wheatley, et al (2008) pointed out that "The nature of employment has changed, increasing the emphasis on flexibility, adaptability, team working and individual responsibility, in both private and public sectors". Work life balance initiatives are likely to have significant economic effects relevant to organisations, including effects on costs, the composition of the labour force, and productivity (Clifton and Shepard, 2004) 
Work life balance issue affect both men and women, it can cause conflict for both men and women leading to neglect of children and divorce. It can affect family satisfaction and frequent mental conflict (Forson, 2013). It is challenging and difficult in achieving WLB in a situation where husband and wife work full time (Wheatley, 2012). Conflict in decision making is always present in such dual career households. However, the practice of WLB can promote the quality of life of the employee through a reduction in work life conflict which might lead to job satisfaction, commitment and loyally to the employers. Moreover, the work life balance issue between men and women can affect business performance (Bourkew, et al, 2010). The wife will require the support of the husband in organizing the domestic works because household roles are usually gendered.

Culture and organizational structure overlap which affect work life balance. The structural dimension is the organizational and institutional forms and pattern in both the work, organization and the family. The pattern of control in the home or work place is the family structure (Evett 2000). The business environment is dynamic and organizational settings do not meet with the changing demand of the work force which can lead to conflict (Shuck et al, 2011). Cultural consideration and the resources of the organization are important aspect of work life balance in determining the experiences of the workers. In some cases, there is incompatibility between business objective and formal work life balance.

Most universities have not been consciously implementing the policies of work life balance. The focus has been that staff should be efficient in discharging their duties without recourse to the emotional feeling arising from neglect of family for work. The policy has not been clearly stated in the Human Resource policy and therefore partial implementation of WLB policies has not been able to address major issues in work place including cross responsibilities and changing nature criteria for promotion.

\section{Methodology}

The research work is carried out using postmodern perspective. One of the conditions of post modernism is that family roles are negotiated rather than given and that culture plays a stronger role in social life. Kwara State University was selected as a case study. The university is a social institution with large number of interrelated roles and which have effects on workers of long period of conferment within these institutions. Moreover, the institutionalisation of these institutions, how they are created and changed, is affected as the pattern of behaviour of workers become settled, routine and enforced by organisational rules (Robert, 2009). These case studies are ways of conceptualising human social behaviour and many things can be learned from the case studies (Glesne, 2011). This can yield exploratory insights on work life balance and the in depth analysis of the two cases will reduce the risk and criticism of a single case study of providing limited generalisation (Babbie, 2013).

Interviews were used as a method of data collection and it was conducted in a face-to-face encounter. Non probability sampling techniques was used in selecting participants and observations that will allow generalisation to people and events that were not observed. The purposive or judgmental sampling is relevant as it is a sample based on the basis of knowledge of a population, its elements, and the purpose of the study (Babbie, 2013). Respondents were selected based on the nature and kind of the job and gender. Twenty eight academic staff and twenty two administrative staff were interview across the two universities. The selection covered different levels of job performance and hence junior officers and senior officers were involved in the interview.

In analysing the data collected categorisation was used. Categorisation was used to make sense of things, to help us see patterns in social interaction (Glesne, 2011; p215). Categorisation is therefore helpful in developing hunches, hypotheses and theories. The purpose is to get multiple perspectives and this will also demonstrate and widens different experiences of life and how society is constructed.

The respondents were categorised into four: Academic staff, administrative staff, senior staff and junior staff. Although, two sets of staff: permanent staff and flexible staff were recognised, however, only the permanent staff were included in the interview. This is because majority of staff in the two institutions are permanent staff. Three important concepts guided the evaluation of this research which includes trustworthiness, reflexivity, and representation. Trustworthiness is important to establish the creditability of the findings (Hartman, et al, 2011).

\section{Research Findings}

It was found that expansion in operation especially creating additional departments and faculties without a correspondence increase in staff put pressure on the staff with increased responsibilities and making work life balance very challenging to achieve.

It was also discovered that job design is a major source of problems for some staff in a situation where there was a blur between the responsibility of academic staff and academic support, For example, some academic staff have administrative responsibility which could be easily handled by academic support staff. 
Week end call out and closing late everyday affect the family of such staff, for example, Personal Assistant (PA) to the Vice Chancellors (VC) whose closing time is determined by the closing time of the VC.

Work life balance is affected by excessive work load. Even if the staff is paid on work, the time spent will affect the time to be spent with the family. However, if the excessive work is not paid and compulsory or discriminatory pay, it will not only affect the time of the staff but the morale and commitment to work. All these affect the planning of time and family of the workers. It was also found that excessive work affect annual leave. It was discovered that some staff found it difficult to plan for their annual leave because of excessive workload.

It was also found that changes in the criteria for promotion put pressure on the work of academic staff. The number of publications and conferences to be attended had increased coupled with other responsibilities.

\section{Discussions}

Work life balance is a growing concept in Nigerian higher education. Respondents gave different reasons and explanation on their perspectives of work life balance. However, they all believed that there is need to work in order to earn a living but gave different reasons for joining higher education workforce.

Most of the participants cited security as the main reason for joining the university as an institution. Family life is secondary to such staff that fear losing their job if they do not work overtime. Pay, or rather the money in the pay packet, is of course, the core of the whole matter. Not only is the cash nexus the only bond between capital and labour but it is also the only direct contact between the family and work place. Assuming that the families were basically dependent on the husband's wage, they had to live on what he brought home. The ambition of all the families was to be able to live within what they could be treated as pleasant extras. These families therefore opted for security.

"My wife understands that we need to survive and we must do everything possible to keep my job. Social life is not so much important to us as the economic life. Therefore working overtime is desirable because it means more money for us"

Extra work content could be due to poor product design, poor work methods, poor management and poor workers- workers fail to start on time, quit early and stretch break times.

"Some workers are lazy and pretending to be working while unnecessarily stressing the work beyond the normal time. Some academic staff would not deliver their lectures at the appointed time but rather arrange lecture time to the convenience and stressing themselves because they have spent their normal lecture hours for other things" Management staff

Most respondents especially from the lower cadre of employment believe that their priority is to survive through gainful employment. Therefore, they strive to retain their work at the expense of their family, health and life.

"What? My family will understand that we need to think of our work, adjust to the demands of the work and satisfy our employer before thinking of our family. We are even fortunate to be employed and we should set our priority right by maintain the job in order to maintain the family" Academic support. Another respondent pointed out that:

".....if you want to earn promotion and progress in your work place, the concept of work life balance should be given less attention except if the concept is appreciated by your employer. It is difficult for me to request for some days off my duty to take care of my family or complain that my work is negatively affecting my family life. A good employer might reply you subtly by saying we all have families and we need to adjust to the requirements of the job".

However, organisations across the globe are promoting different work-life balance policies to augment balance between the domains of work and non-work of their employees. This is because WLB is conducive to lowering employee turn-over, reduce burnout, increase productivity and loyalty, and on the basis that it can help to achieve happier and healthier lives among the workforce (Kanwar, Singh, and Kodwani, 2009; Williamson, Lewis, and Massey, 2011).

Similarly, some responds do not even have the confidence to discuss their family issues and how the work is affecting their life. "I can't discuss my work in relation to my family with my boss. The tendency is that I will be regarded as unserious staff and my boss might have negative impression about me.

Considering the time spent with your family is a key to work life balance, however, it also includes a consideration of time spent outside your work such hobbies, sports, or other social activities (Thomson, 2002). Work is the key source of stress and work related stress is an illness which should be treated as such (Thomson, 2002). One way of reducing this stress is through improved job design. A respondent explained that:

"Job design is one of the factors affecting the time that I spend for my family. The job needs to be redesigned to allow for flexibility and reduce the pressure on the staff. Additional responsibility to a particular job naturally increases the number of hours to complete the job leading to a reduced time for my family". 
The use of shift work presents a conflict between the economic goals of the organization and the sociocultural goals of the workers. Many workers prefer to work during the day and the week rather than the night and the weekend. Night and weekend work tend to interfere with sleep and make the workers live independently of their families. Leisure time of shift workers tend to have a lower value since it cannot be exchanged for many common leisure activities. This reflects some of the workers' social difficulties. Some organisations pay premium wages to compensate for these problems.

Culture is another major factor affecting work life balance. In some cultures in Nigeria, men are regarded as the bread winner of the family. Even though women are now taking paid jobs, yet their husbands are still regarded as bread winners in the family. Wives rarely bothered to ask about their husband work. None of the aspects of their husband's jobs were their immediate concern. Working conditions and management alike were simply part of what the men had to endure to bring home a pay packet.

"My wife never asked me about my work but she would simply ask only if stay too long in the office.......out of love"

However, there were aspects of their husband's work that they did feel qualify to talk about. These were most notably pay, shifts and overtime, which daily and directly affected home life, and safely, redundancy and promotion, which could affect it. The issue of working shift and overtime affected the wives as materially as their husbands. Virtually everyone said that shift work interfere with their social life.

\section{Implications}

The concept of WLB has implication on both the work and family of staff of the institution. If there is imbalance and excessive work at the expense of the family issue, it could result to family problems including aggression, frequent misunderstanding and divorce. Aggression and family problems are major factors that are responsible for continuous decline in workers' performance. Some of these family problems are work related.

"My wife is not always happy when I work late and the reaction is always counterproductive the following day. While at work, I will be preoccupied with the thinking of the behaviour that my wife would exhibit if I fail to return home at the normal time. This affects my concentration especially if it is necessary for me to continue working after the official working hours".

\section{Another respondent said:}

"I do feel tired and exhausted after working for more eight hours a day. It is quite frustrating as well when you see your colleagues going home and you are required to continue working and definitely the rate of my performance use to be slow if I am tired". A lecturer said "It is worrisome that sometimes I have to leave or abandon family issues unattended because of the nature of my job. I spend more time at work and when I get home, there is little I could do to make my family happy except to go to bed".

Work life balance is another source of frequent mistakes committed in the work place. Most mistakes are as a result of fatigue and stress arising from imbalance in work and life. For example, a staff that is not emotionally stable because of family problems is likely to make mistakes in the work place.

"Most of the mistakes are always from lack of concentration on my work. Tiredness and fatigue are major sources of distraction because of inadequate sleep. I have so many things to do which is giving me sleepless nights. I need to rest but my wife will not support or encourage me to work whenever I get home. It is really hectic for me". Academic support

Carelessness of the workers arises as a result of stress from prolonged hours of work. Most quality problems are due to poor management but small minorities are from worker carelessness.

The level of innovation is reduced with excessive work load. Although there are no best way of doing things, staff will only have innovative ideas if they have the time to think of better way of doing things.

"I have so much work to do that I cannot complete in the office. What better way of doing things than to take my work home. It is good to innovate and do things in a different way but the fact is that the workload is too much for me to contain" Management staff

However, some respondents claimed that it is the pressure of the work and excessive workload that will necessitate finding alternative way of reducing the time and doing it efficiently. Routinisation of work is monotonous and may not be advantageous in certain circumstances:

"Our work is dynamic and we must constantly be thinking of the best way of doing things so as to be efficient. Moreover, we need to innovate in order to meet the challenge of the changing world. Innovative ideas and creativity of staff will enhance his or her job promotion and job mobility". Academic staff 


\section{Conclusion and Recommendations}

This paper has been able to identify that the concept of work-life balance is a major factor that is affecting workers' performance and productivity in Nigerian higher education. The work life balance issue in Nigerian higher education is affected by many factors including expansion in work operation, job design and excessive work load. The imbalance in work life can result to stress and it can affect job performance and productivity. The paper also discovered that the concept of WLB can have other implications on the family such as aggression, frequent misunderstanding and divorce.

It is recommended that the issue of work load should be given greater attention. Monetary rewards of excess work load may not solve the negative impact of WLB on the job as well as the family life of the workers. Our higher educational institutions should be reformed to allow for greater flexibility. Employee flexibility will allow for concentration in the work place and improve on worker's innovation. Moreover, employer flexibility would improve employee's efficiency and also help employers to respond to economic conditions by enabling them to "pull in" or "push out" labour depending on the point in the economic cycle and the need for them.

Workers' jobs should provide closing time and an obvious relationship between tasks. This requires the performance of tasks which might be regarded as a daily work for specific hours stimulated in the condition of service. Individual job design is completed by consideration of work methods which will take into cognisance the work life balance issue. Management should be considerate in allocating administrative responsibilities to academic staff with a view to allowing them enough time to carry out research work and other responsibilities associated with academic work.

\section{References}

[1]. Adeyemi, O. (2001) Moving Nigeria Forward. The Development Planning Approach. Ibadan: Ibadan University Press Publishing House, Nigeria.

[2]. Akpan, P. A. (1987) The spatial aspects of higher education in Nigeria. Higher Education. 16 p. $545-555$

[3]. Atkinson, C. And Hall, I. (2009) The role of gender in varying forms of flexible working. Gender, Work and Organisation. 16 (6) p 650-666

[4]. Babbie, E. (2013) The practice of social research. Australia. Wadsworth Cengage Learning.

[5]. Bourke, J., Pajo, K. and Lewis, K. (2010), "Elder care and work-life balance: exploring the

[6]. Burke, R. J. and McAteer, T. (2007) Work hours and work addiction: The price of all work and no play. Research in Occupational Stress and Well Being. 6 p. 239-273

[7]. Carlson, D.S., Grzywacz, J.G. and Zivnuska, S. (2009), "Is work-life balance more than conflict and enrichment?" Human Relations. 62 (10) p. 1459-86.

[8]. Cegarra. Leiva, D., Sanchez.- Vidal; M. E. and Cegarra - Navaro J. G.(2012) Understanding the link between work life balance practices and organizational outcomes in SMES. The mediating effect of a supportive culture. Personnel Review. 41 (3) p 350-379

[9]. Clifton, T. J. and Shepard, E. (2004) Work and family programs and productivity Estimates applying a production function model. International Journal of Manpower. 25 (8) p. 714-728

[10]. Dimensions", Gender Work and Organization. 7 (1) p. 57-67.

[11]. Eikhof,D. R., Warhurst, C., Hawzchild, A. (2007) Introduction: What work? What life? What balance? Critical reflections on the work life balance debate. Employee Relations. 29 (4) p 325-333

[12]. Evetts, J. (2000), “Analysing career change in women's careers: culture, structure and action

[13]. experiences of female small business owners", New Zealand Journal of Employment

[14]. Felstead, A., Jewson; N.,. Phizauklea, A. and Walter, S.(2002) Opportunities to work at home in the context of work-life balance. Human Resource Management Journal. 12. p. 54 -76.

[15]. Fleetwood, S. (2007) Why work life balance now? International Journal of Human Resource Management. 18 p 387-400

[16]. Forson, C. (2013) contextualizing migrant black business womens' work - life balance experiences. International Journal of Entrepreneurship Behaviour \& Research. Vol 19 NO 5 P. $460-477$.

[17]. Glesne, C. (2011) Becoming qualitative researchers. An introduction. Boston. Pearson Education, Inc.

[18]. Hartmann, D.P., Pelzel, K.E., Abbott, C. B. (2011) Design, measurement, and analysis in developmental research In Bornstein, M. H. And Lamb, M. E. (eds) Cognitive development. An advanced textbook. New York. Psychological Press.

[19]. Lewis, S., Gambles, R. And Rapport, R. (2007) The constraints of a "work life balance" approach: an international perspective. International Journal of Human Resource Management. 18 p360-373

[20]. McDonald, P., Townseid, K., and Wharton, A. (2012) The legitimation and reproduction of discourse-proactive gaps in work-life balance. Personnel Review. 42 (2) p216-222

[21]. Relations. 35 (1), p. 17-34.

[22]. Robert, K. (2009) Key concepts in sociology. New York. Palgrave Macmillan

[23]. Shuck, M.B., Rocco, T.S. and Albornoz, C.A. (2011), "Exploring employee engagement from the employee perspective: implications for HRD”, Journal of European Industrial Training. 35 (4) p. 300-25.

[24]. Sturges, J. and Guest , D. (2004) Working to live and living to work? Work-life balance early in the career. Human Resource Management Journal. 14(4) p 5-20

[25]. Thomson, R. (2002) Managing people. $3^{\text {rd }}$ edn. Oxford. Butterworth-Heinemann.

[26]. Waller, A. D. and Ragidall, G. (2012) The impact of email on work-life balance. Aslib Proceedings: New Information. 64(2) p 154177

[27]. Wellington, J. and Hammond, M. (2013) Research method. The key concepts. London. Routledge.

[28]. Wheatley, D. (2012) Work-life balance, travel to work, and the dual career household. Personnel Review. 41 (6) p 813-831

[29]. Wheatley, D., Hardill, J. and Green, A. (2008) Mobile work and challenges for public policy in Hislop, D. (ed), Mobility and Technology in the workplace. Routledge. Oxford. P 227-239 